

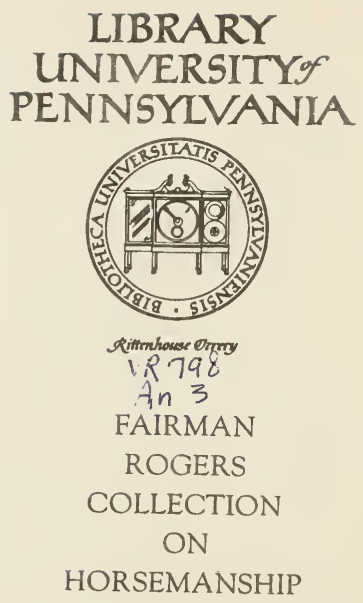


Digitized by the Internet Archive in 2009 with funding from

Lyrasis Members and Sloan Foundation

http://www.archive.org/details/viceinhorseoth00ande 




VICE IN THE HORSE 
$23 p$ the same autfor.

\section{MODERN HORSEMANSHIP:}

\section{A NEW METHOD OF TEACHING RIDING AND TRAINING}

By means of Instantaneous Photographs from the Life.

Vow and Revised Edition, contaning some observations upon the mode of Changing Lead in the Gallop.

In 1 vol. demy 8io, price' $2 \mathrm{~s}$.

'I master of the craft.'--Illustrated Sporting and Dramatic Nezus.

'A practical and very accomplished horseman. The fact is obvious from his book.'-Saturday Revieze.

'The book is liberally furnished with instantaneous photographs, which illustrate and explain the author's text.'-St. James's Gasette.

'Every detail connected with saddle, bits, and bridles, with mounting and leaping, is dealt with in the most thorough manner.'-Harper's ITagazine.

THE GALLOP.

Iately Published, in I vol. foolscap 4 to, 2s. 6al. Illustrated by Instantaneous Photography.

EDINBURGH : DAVID DOUGLAS. 


\section{VICE IN THE HORSE}

AND OTHER PAPERS ON

\section{Horses and Riding}

BY

EDWARD L. ANDERSON

AUTHOR OF 'MODERN HORSEMANSHIP,'

ETC. ETC.

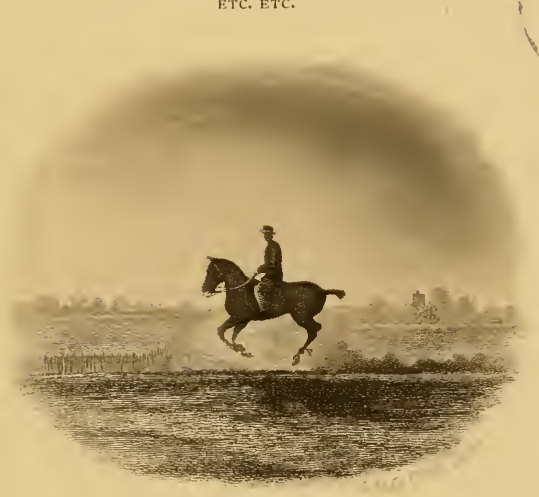

EDINBURGH : DAVID DOUGLAS

MDCCCLXXXVI 



\section{CONTENTS}

IICE IN THE HORSE, . . . PAGE

ON THE VALUE OF BOOKS ON RIDING, . . 12

WHAT SCHOOLING WILL DO FOR A HORSE, . . 21

THE INTELLIGENCE OF THE HORSE, . . . 30

SHOEING THE SADDLE-HORSE, . . . . 35

THE TEST OF HORSEMANSHIP, . . . . 40

HOW TO BUY A HORSE, . . . . . . 47

A MODEL RIDING-SCHOOL, . . . . 55

THE CHANGES IN THE GALLOP, . . . . 60

\section{ILLUSTRATIONS.}

ALIDOR AT FIVE YEARS OF AGE, . . to face page $2 \mathrm{I}$

THE CHANGES IN THE GALLOP, . . . . 62 



\section{Vice in the Horse.}

WHEN we consider the rough and crude methods that are usually employed in training and educating our horses, we should not be surprised that every year thousands of these animals are rendered dangerous to those who ride or drive them. Doubtless many over-fed and under-worked horses become difficult to manage in the hands of irresolute or timid owners; but such animals can readily be brought back to a state of discipline by a strong and determined rider. By far the greater number of really dangerous horses have been made vicious by the incompetency of those who have undertaken to prepare them for usefulness, and it is the more difficult to correct the faults of such horses, seeing that there has never been any discipline which might be re-established.

To one who has had experience in the training of young horses, it is easy to imagine the steps by which a generous and spirited colt is brought to a condition of continuous and active mutiny. An itching skin, a pinching saddle-tree, a tender mouth, 
may induce a young and undisciplined horse to rub itself against a wall, to crouch, and even to lie down, or to throw up its head, and perhaps to rear. The breaker at once sees, in these ordinary actions of an animal that has hitherto been permitted to follow its own devices, signs of a vicious and headstrong disposition, and he flogs the horse for doing that which was, under the circumstances, natural and without sinister motives. The next time that the colt wishes to scratch its side, or feels the pinching of the saddle, or is hurt by the bit, it will remember the punishment that followed its previous effort for relief, and, nervous, excited, and foreboding evil, but still in ignorance of any real wrong on its part, it will rush up to the wall, or throw itself down, or rear higher than it intended. Another whipping, and we have a dangerous habit fixed in the animal's mind, a habit that cannot be eradicated under the course of treatment by which it was induced, and therefore in all probability the horse becomes vicious.

Because certain of the movements that are employed in the schools for disciplining the horse are used for show in the circus-ring, there is now a prejudice against anything that savours of the manége. These movements are useful in preparing horses for any purpose, although not abso- 
lutely necessary in training well-disposed horses for ordinary hack-work; but the 'suppling' and 'uniting' that form the groundwork of the school methods are of the highest importance, for by their means the horse is most easily and quickly taught to obey the bit and the heels, and to carry itself gracefully and lightly. The few good horsemen who do not follow the school method ride their horses up to 'the union' between gentle tension upon the reins and cautious pressure of the spurs ; but this takes much longer, and is more difficult to accomplish than to bring about the union of the extremities between hand and heels after the horse has had the preparatory lessons on foot, by which the meanings of the indication of the bit and spurs are gradually taught.

There are few cases of vice in the saddle-horse that cannot be prevented or cured by the school method of training, for by easy lessons the horse is so disciplined that obedience becomes a habit.

Nearly every horse finds certain forms of resistance easier than others, and this is due in a great measure to the conformation of the animal. ${ }^{1}$ Horses

1 A horse with a stiff, unyielding jaw, and a horse with a tender mouth, will be apt to rear; the first, because it opposes the hand until the bit hurts it, the second, because even a slight pressure of the bit is disagreeable. A horse with a 'roach back' is more likely to plunge than one that has a depression between the withers and the croup. As a rule, the horse with a 'dished' face is nervous, the horse with a Roman nose is headstrong, and the horse with a small protuberant eye is suspicious and excitable. 
that are high and strong in the fore-hand are more apt to rear or grow restive than horses which are high and strong in the hind-quarters. The latter will usually resist control by bolting or by kicking. The reasons for these kinds of misconduct is that in the horses first described the weights and forces of the fore-hand are thrown back, and that part is made lighter ; while, in the case of horses with high and strong hind-quarters, the weights and forces are thrown forward, and the fore-hand is hampered while the croup is lightened. The disposition of the horse will usually be influenced by its conformation, certainly its resistance will in most cases be governed by its conformation.

A well-balanced horse, that can obey the demands of its rider with more ease and comfort than an ill-formed one, is less likely to show vice, and generally has a better temper than the horse that is ill-balanced. The first duty of the trainer, then, should be to direct his work with reference to the conformation of the animal he has in hand, and, by changing the carriage of the horse, to correct in effect its faults of form, so that it may not find difficulty in obeying the hand and heel of its rider.

Whatever may be the form of a horse, it must be suppled in the neck and jaw so that it will answer to the bit at the lightest pressure upon the bars of 
the mouth, and will raise or depress the head at the demands of the hand. It must also be taught to answer the pressure of the rider's heels without reluctance or struggling. The horse that is too high in the fore-hand can then be taught to move with its head so lowered, and its hind-quarters so well brought up that the weights and forces may be brought to a point of balance under the rider, so that the movements of the animal can easily be directed. As long as the jaw yields to the bit, and the croup answers to the heels, the horse will neither rear nor grow restive; and it is a mere question of time and patience to confirm the horse in this obedience, for, as I shall show, the impulses of the horse are cultivated in the direction of this obedience, and it answers to bit and spur instinctively.

The horse that is low in front and strong and high in the hind-quarters will be made to move with its head carried up, by which means the weights and forces of the fore-hand are carried back, while the hind-legs will be brought under the body to lower the croup, until the weights and forces of the extremities are brought to a point of union and balance under the rider, and the horse will have no difficulty in answering the demands of its rider. It would be impossible for a horse 
so trained to bolt or to kick, for the rider can bring the hind-legs of the horse under the mass, and with the hand throw back the forces of the fore-hand, and so bring it to an instantaneous halt from any pace.

I wish, in a few words, to explain what I mean by cultivating the impulses of the horse in the direction of obedience, for in that lies the whole success of the school method. The first impulse of the horse upon feeling the pressure of the bit against the jaw is to yield; the second is to oppose the pressure. The first impulse of the horse on feeling the touch of the spur is to draw forward the hind-legs; the second is to extend the flexed hind-legs. By carefully-conducted lessons these first impulses, the instinctive muscular actions of the animal, are cultivated, until the hand controls and directs the fore-hand, and measures the propulsion from the hind-quarters. In ordinary training, as must occur to any reader, the second impulses are unwittingly cultivated to the detriment of the first impulses, for most horses wait for a more or less forcible reminder from the bit, and spring forward at the touch of the spurs.

Doubtless the greater number of horses that are in daily work were trained without reference to ' the point of balance of the forces,' but all horses that can be ridden, whether intentionally or not, are 
to a greater or less extent taught obedience through their instinctive yielding to the aids; and it cannot be contended that those broken by rough and crude modes are under the same control as that exhibited by horses which are prepared by discipline and an acquired equilibrium to instinctively obey every demand of their riders.

One is often called upon to ride a difficult horse before he has had an opportunity of training it sufficiently to compel its obedience, and under such circumstances I think the following suggestions may be of value. It is of the first importance in riding a vicious horse to keep it moving, never permitting it, when showing signs of temper, to come to a stop. If a 'fresh' horse makes a few curvets or leaps, the rider should not at once confine the head too closely, but, holding the reins so that the animal cannot get its head down, make it advance, and then gently bring it back to a quiet pace, and afterwards increase the speed if it be desirable. To check or to punish the horse at the moment it is restless will induce the animal to rear or to plunge. If a horse rear, the rider should release the tension of the reins, and press his legs against the animal's sides at the moment the fore-hand comes down, to drive it forward; but the spurs should not be applied with severity, for that will 
not cure the horse of rearing, and may add plunging to its vices. A horse can be cured of the vice of rearing only by the suppling of the jaw. If a young horse rears without malice, as many do in their early lessons, a light tap on the neck and a harsh word from its master will often prevent a repetition of its action, but a horse should never be punished for vice. For many years I have kept my horses at riding-schools where the masters undertook to break the horses of their patrons from bad habits. I have seen all kinds of methods employed, and I have myself tried all, and I never knew severity to succeed; but I have often seen horses that were dangerous to ride made safe and quiet by a kind and strict discipline. A really vicious horse works itself up into a rage, and punishment can do nothing more than to increase the violence of its madness. If the horse cannot be brought to know that the rider will not hurt it, the animal must remain incurably vicious. If the rider can obtain the confidence of his horse, he may then cultivate its obedience, until to yield to bit and spur becomes instinctive; but I believe that there are some horses which cannot be broken from bad habits, and any of them are liable to relapse into vice through injudicious treatment.

Most young horses plunge, more or less violently, 
for the first three or four times they are mounted. If at this time the animal is not carefully ridden plunging may become a vice. When a horse plunges it must be driven forward in any pace or action that it will take, the rider giving it a loose rein, but taking care that it does not get its head down, for the horse will then stop in spite of all the man can do, and probably unseat him. I mean by giving the horse a loose rein, that it should not feel the restraint of the bit, but if the animal lowers its head, the rider should give one or two sharp pulls upward to elevate it. When the horse goes forward for a few strides, the rider should take a light tension upon the reins, and gently regulate the pace and the direction. Many horses will plunge if mounted immediately after being saddled, and it is a good rule to have all horses saddled at least half an hour before they are used. In winter the bit should be warmed before being put on the horse, and it would be an excellent plan to have all bits covered with hard rubber or some other non-conductor of cold. If a horse kick, its head should be elevated by short, sharp pulls upon the rein, from below upward, and the animal driven forward, the rider correcting the fault by speaking harshly. Whip blows will almost invariably confirm the horse in the vice, and will teach the animal to cringe and 
to start at any movement of the rider. A bolting horse may be prevented from indulging in its vice by the rider applying both spurs, leaning back his body, and raising his bridle hand. I believe that any horse may be brought from moderate speed to a halt, without any previous special training, by this method. When a horse has broken away from all control, and madly gallops on with his unwilling rider, there is nothing to be done but to make occasional efforts to recover command of the horse's mouth, for by a steady pull the rider would too soon exhaust himself. If there be a 'rough-and-ready' cure for a runaway horse, which I doubt, it consists in riding it to a stand-still. But a determined rider can prevent the horse getting away with him by using the spurs as I have directed. If a horse 'shies' at an object, the most injudicious thing a rider can do is to make the animal face it. By turning the horse's head away from the object, and pressing in his opposite heel, the rider can compel the horse to pass anything, and the bent position in which the horse is placed will prevent it going in the direction it wishes, that is, away from that of which it is afraid. After the animal has been made to go by the object. the rider should calm it by caresses and kind words, and in time it will lose all fear of strange sights, 
for, having obtained confidence in respect to one thing that has caused it fear, it will be less shy of others that are strange and terrifying. A horse may be taught in a few lessons to face flying paper, banners, etc., if it be fed on carrots laid upon a piece of paper, and be gradually accustomed to have the paper afterwards flourished in its face, and then placed upon the ground for it to walk over. I may say here that an unwilling horse may be led almost anywhere if the man will walk quietly forward with his back to the animal.

I believe that the methods I have described are the best that a rider can employ in controlling difficult horses, but vice can be repressed or cured only by suppling the horse, and teaching it to instinctively obey the bit and the heels in the manner I explained at the outset. There are very few horses that cannot be made, by skill and patience, perfectly obedient, and once the theory of such a method is acquired there is neither difficulty nor danger in following it. 


\section{On the Value of Books on Riding.}

IT has been said by some would-be authorities on Horsemanship that books on riding are of no value. But, admitting that every one can find a master competent to instruct in the best methods, it seems to me that works on the subject fulfil an important part if they preserve and hand down the traditions of the art. But written words convey very much the same meaning as do the same words when spoken, and there should be no difficulty in any one, who can comprehend the instruction of a master, understanding the precepts of a book. It is more probable that the printed work is in accordance with a good method than that the instructor knows his duties. It is very easy to find a work that is written upon sound principles, but it is a difficult thing to choose a competent instructor. A riding-master should certainly ride well enough to make his horse change the lead in the gallop, at stated intervals, in a straight line. For it is important that his pupil should be able to make a 
horse take a desired lead preparatory to turning in the gallop, and the tutor should have a practical knowledge of what he is to teach. I repeat, that I think it would be difficult to find such an instructor. I contend that a pupil would learn more from a thoroughly good book than from a teacher who is ignorant of what he undertakes to teach, and I deny that there is any insuperable difficulty in acquiring a thorough knowledge of the art from a book. The proper position to take upon the horse, the mode of using the reins, the manner and objects of applying the spurs, can be plainly told in printed words, and as a test whether the combined effects of the aids to produce certain results can be explained in type, I will describe the method of demanding the most difficult movement in horsemanship-the change in the gallop,- - and ask the reader if he could not, after proper practice, carry the instructions into effect.

First, it must be understood that in the gallop the horse goes into air from a fore-foot-say the right; he then alights upon the left hind-foot; then he brings the right hind-foot and the left fore-foot to the ground, and then the right fore-foot (from which he again goes into air in a new stride).

Now, to the eye the horse has taken longer steps with the legs of the right side, because they are 
advanced at each stride, while the left legs have been used like wheel-spokes, and the horse is said to lead with the right side.

The horse, in turning in the gallop, should lead with the legs of the side to which he turns; so that, if he be leading with the right legs, and the rider wishes to turn to the left, the lead must be changed.

At first the young rider will not have the skill to apply the aids quickly enough to make the change while in the gallop, so he will pull his horse into a slow trot, hold him well together between his hands and his heels, and then press in the right spur, and pull upwards on the left rein, when his horse will resume the gallop with the left legs in the lead.

After some practice in this method he will try to make the change without breaking the gallop, the right side being in the lead.

To do this he will collect the horse between hand and heels in as slow a pace as the horse will keep steadily, then, to catch the cadence of the pace, he will count, 'one,' ' two;' 'one,' ' two,' etc. ; the word 'two' to be uttered as the fore-hand comes down in each stride. At some moment when the rider counts 'two' he should press in the right spur and raise the left rein, retiring at the same time the left shoulder. If the aids be properly applied at the right moment, the horse will change the lead of the 
hind-legs when they are free from the ground (at the moment the weight has been taken by the right fore-leg), and it will change the fore-legs when they are free from the ground (as the horse goes into air for the next stride). The horse will then have made the change of lead, and be true in the gallop with the left legs leading.

The change from the left side to the right will be made in exactly the same manner by the corresponding aids; that is, the left spur and the right rein will be applied as the fore-hand comes down in any stride.

I believe that I am the first writer on horsemanship who has undertaken to describe and explain this method of changing the lead in the gallop, so that I have not had the example of any predecessor in making myself clear; and if the reader can understand the movement, he should be able to grasp the meaning of any accepted method.

The pupil must not expect to be able to make the horse perform the movement I have described at the first trial, or before many trials. That is not the question. Does he understand the principle? and, after sufficient practice, could he put it into effect? If these are answered in the affirmative, then books on riding may be of value. It must take a long time before a beginner could use spur and rein with suff- 
cient precision to make the horse change the lead in the gallop, but, without a knowledge of some method, he would never be able to do it. All that a ridingmaster could do would be to make the pupil understand how to use the aids; he could not apply them for the pupil; he could not do anything beyond what the book can do,- and there are very few ridingmasters who can do as much.

The value of a riding-master's example is small, if it have any value. On the Continent the instructor is often on foot. He is only of advantage as a critic, to tell the pupil when he is wrong; but if the pupil knows what is right, as he may know from a book, he can be his own critic. I do not say that a book is as good an instructor as a practical teacher would be, but I do say that it is better than no teacher, better than an incompetent teacher. Certainly a pupil would not be able to ride from reading a book, without getting upon a horse to practise what he had learned; neither would he acquire any great proficiency by sitting in a chair while a teacher expounded the rules of the art. I have read nearly every important work on horsemanship that has been written since Xenophon thought fit to put into undying words all that he knew of the art, and I am sure that I have learned a great deal from them, and I would undertake to 
teach a horse any movement for which the animal was suited by the rules of any good modern work.

The art of horsemanship has grown slowly. A man would never acquire any great skill in it by his unaided efforts. But when he has learned all that has been collected and handed down by those who have written upon the subject, he may discover new and valuable effects of the bit and of the spur. If it be necessary to prove that books on riding have advanced the art, let us look at the strides that have been made in it since the invention of printing. Let us compare the work of Grisone, published in I 552, with that of Xenophon, and then compare one of the best modern works with that of the Italian. We shall see that Grisone's method is little, if any, in advance of the work written two thousand years before; it is rough, crude, severe, and difficult for horse and man. Then if we trace the history of the art through Pluvinel, Newcastle, De la Gueriniere, and Baucher, we shall find in the almost perfect methods now in use the great advance that has been made in the past three hundred years, - an advance that is certainly due in a great measure to the printing of books upon the subject. Grisone's was the first work that appeared in type. In a few years there were works published in nearly every European 
language. Each new work stimulated public interest in the subject; each new work preserved all that was good in its predecessors, and made known the discoveries that were due to this increased interest in horsemanship. If it were not for these books, the art would be in much the same condition that it was in Grisone's time, when sticks and stones played a prominent part in the education of the horse. The prejudice against works on riding has been fostered in England, to the disadvantage of every one who rides, by writers in the sporting papers who are ignorant of the first principles of horsemanship. Although but few men on the Continent, as compared with those in England, turn their attention to riding, there is hardly a country in Europe in which there are not more really fine horsemen than in England. Upon the Continent riding is looked upon as an art; in England every man thinks that he is born a horseman, and scorns instruction. Upon the Continent the test of horsemanship lies in the control of the horse; in England the test of horsemanship lies in the ability to ride to hounds, a sport into which many conditions other than that of mere skill in horsemanship enters. The English are the boldest, and if they understood and followed good methods they would 
be the best riders in Europe; but, with very few exceptions, they are awkward and unskilful in the management of their horses, and the latter are unbalanced, disunited, and badly controlled. Should my opinion be questioned, I will ask how many horses in Great Britain can be shown that are perfectly trained to obey bit and spur, so that their riders may demand the changes of lead in the gallop on straight lines, the pirouettes, and the other movements that any cavalry soldier might be called upon to make in battle, and such as all who pretend to be skilful in the management of a horse should be able to produce. The methods by which the horse and the rider may be brought to such a state of training as that indicated above can be formulated and preserved only in works on horsemanship. Even though such methods were now known by instructors, they could not be handed down intact by tradition, and improvements and discoveries could not be made public and useful except through the press. If the English are the best riders, what riders have they produced in modern times who can be named with Baucher, De Montigny, Hunersdorf, Von Weyrother, Hamel, Seidler, Gebhard, and others? If they are not the best riders, it is not for want of that 'practical experience' upon 
which so much is said to depend, but because the practice is not properly guided; and there can be no improvement in the horsemanship of Great Britain until riding is recognised as an art that cannot be acquired empirically. 



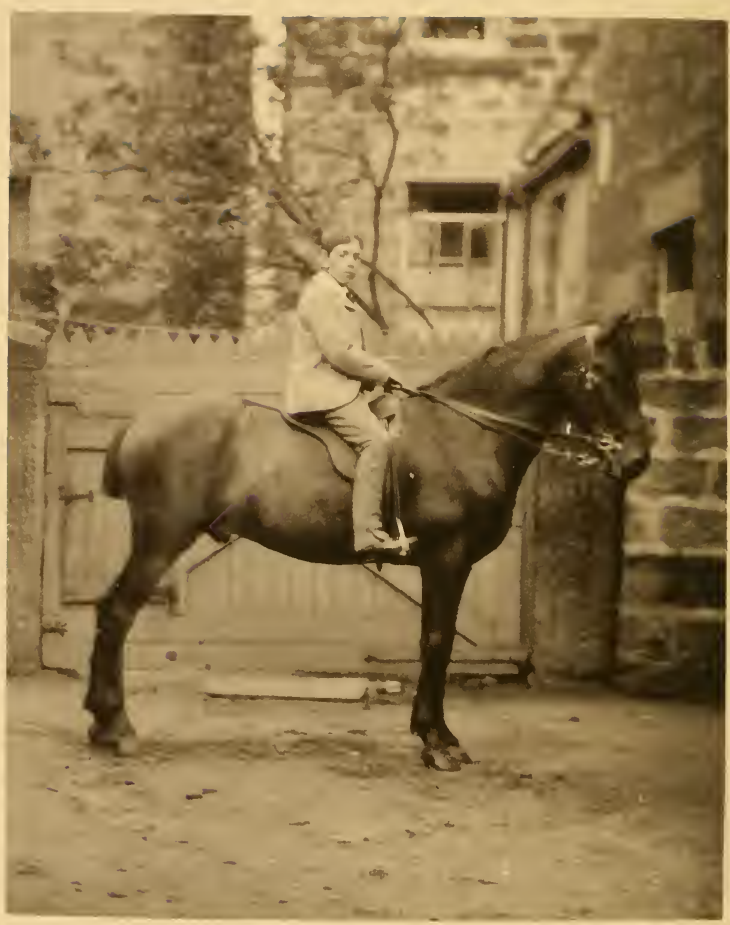

Alidor, at 5 years of age.

From a photograph by T. \& J. Holroyd, Harrogate. 


\section{What Schooling will do for a Horse.}

Aт the time I was training Alidor, the horse that furnished the photographs for my work on Modern Horsemanship, I sent the following paper to The Field. I did not offer my name for publication, because I did not wish to take advantage of the columns of that paper to puff my books on riding, but the Editor was furnished with my name and address, and the titles of my published works.

To my surprise and mortification the next issue of The Field contained the following note in reference to my communication :-

'X.-Your statements are so incredible, that we cannot insert your letter unless it is authenticated by some well-known signature.'

The Editor afterwards explained to me that he objected to my article, upon the ground that the alleged results of my training differed from those of his experience; and he declined to investigate the matter, or to retract his offensive remark.

I will say nothing of the taste displayed by an 
Editor who invites correspondence, to insult the writer whose contribution he declines. But when he takes his stand upon a doubtful experience, I feel privileged to investigate his pretensions, and certainly it is incredible that the Editor of The Field should have had the experience in training horses in the thorough manner he intimates in his note to me, and he therefore had no right to question the results of my work.

The Editor of The Field is the author of a work on horsemanship-Riding and Driving, by Stonehenge,- - which proves that his knowledge of riding is of the crudest and most limited kind, for the instructions it contains are about such that one yokel would give another in taking a farm-horse afield. In attempting to describe the passage on two paths-which this experienced trainer misterms passaging, as if the action indicated the side progress-he states, in his work on riding, page 49 , that it is a movement in which the horse advances the two legs of the side towards which it is going, and then brings the other two up to them. This is absurd; the passage is a trot, in which the diagonally disposed legs move together, and the author of Riding and Driving did not know the action in one of the most important of the school movements. He advises that the rider should 
seize the ear of the horse to bring it to a trot (page 33). Let us imagine the appearance of a cavalry regiment, instructed according to the theories of the Editor of The Field, when the colonel should give the order to advance at a trot! Here we see that the author is not aware of the simplest effects of the bit. To make the horse take a certain lead in the gallop, this author recommends that the rider should 'pull the animal's head to the opposite side, so that the horse would become habituated to lead with the left side when turned to the right, and with the right side when turned to the left, and so be insured to be false in the lead at all the turns. On page 52 this experienced horseman speaks of a good hack 'wholly unable to canter, and so formed that he cannot be taught.' There is no horse so formed that it cannot be made to canter. The plan 'to check' a horse with the curb-rein for stumbling, is worthy of the other precepts in this instructive work; and when he advises that 'the hand and foot are put strongly out,' to prevent the horse crushing the rider's knee against a wall, instead of suggesting that the animal's head should be pulled into the object, he further exposes his incompetence to give instructions in riding. Is it possible that a writer who recommends (page 48) that 'the bit may be 
gently "sawed" from side to side' to make the horse back, knows anything about collecting the horse in the form that makes a retrograde movement easy to the animal?

It is not worth while to continue the investigation of a book on nearly every page of which the author shows his complete ignorance of his subject, a work that nowhere exhibits the slightest knowledge of that 'union' which made everything I asserted regarding the horse I described in my letter easy and credible. The instructions offered in the columns of The Field, and for which its Editor is responsible if he did not-which is in most cases probable, from their nature-write them himself, are no better than those I have extracted from his book. In 'Answers to Correspondents,' I found the following extraordinary piece of information :- 'If a horse's head is turned to the left, he must of necessity advance his "off" fore-leg. In cantering round a ring the same thing takes place;' that is, in galloping in a circle, the horse must lead with its outside legs, which would make the animal false. In the same department I have found other such absurdities; for example-that if the horse does not rear to a dangerous height, the rider should do nothing; that the horse should be struck upon the right shoulder to induce it to 
take the lead in the gallop with that side; that the barbarous plan of placing a sharp spike in the mouth-piece of the bit of a horse that pulls on one side is advisable; that the toes of the rider should be turned out, which would take the flat of his knees away from the saddle, etc. etc. The knowledge exhibited in the editorial columns of The Field, and in the reviews of works on riding, is often in keeping with the extracts I have already made from its first page. One leading article, I remember, spoke of horses that poked their noses to the ground, 'like pigs hunting truffles,' or that held up their noses like 'star-gazers,' as if it were not bad riding that induced such carriage, for in a state of nature no horses so bear themselves; and I have more than once seen pirouetting and traversing decried as circus-tricks, while the importance of changing the lead in the gallop was admitted, when any horseman knows that to teach the horse to bend the croup to make the changes in the gallop, the animal must be trained in the pirouettes and traversing. This paper has frequently recommended that the martingale should be put on the curb-reins, in which suggestion we have proof of complete ignorance of the mechanical action of the curb-bit, for the effect of the lever would be destroyed by the interposition of the 
martingale. 'This is the 'authority' who, relying upon his experiences in training horses, stigmatises my statements regarding the results of a thorough system as 'incredible.'

Representatives of The Times, of Vanity Fair, and of The Illustrated Sporting and Dramatic Nezus, who saw me ride Alidor, all stated in their papers that the horse was formed as I set forth, and that at the time they saw it ridden, it was remarkably light, easy, and graceful in its movements; and the Editor of the last-named paper, who had read my letter to the Editor of The Field, added that in that communication I had kept far within the bounds of truth. I have certificates from the vendor of the horse, and from the proprietor and the head groom of the riding-school where the horse was trained, that the animal was at first in the condition I described. Finally, the illustrations in my book, taken when Alidor was six years old, and had greatly improved in form by age and by the exercises of the manege, show that he has a heavy jaw, a short neck, and is low at the shoulder, and that he is remarkably well trained.

To one who knows anything about training all of this will appear a ridiculous contention, for there was nothing strange in the fact that a young horse should be greatly improved in carriage and appear- 
ance by a careful mode of schooling; and I wish to say that the letter was written solely with a view of reviving an interest in Baucher's system of training, which I consider by far the best that has ever been offered to the public.

A very good example of what training can do towards making horses light and graceful in carriage was recently offered in the Circus Wulff in Vienna, when several of the heavy Percheron draught-horses were exhibited in the airs of the high school. Their performances were highly applauded by the most critical audience in Europe, and they were pronounced by the Sport-Zeitung (of July 31, I885) to have moved 'lightly' and 'brilliantly,' notwithstanding the apparent heaviness of 'horses of the heaviest kind.'

The following is the article alluded to, copied from the carelessly written letter that was intended only as a casual contribution to the unpaid columns of a newspaper :-

\section{- To the Editor of The Field.}

'Sir,-About eight months since I purchased a horse from Mr. M'Indoe, Davidson's Mains, Cramond, for the sum of twenty-five pounds.

' The animal in question was a four-year-old gelding, with a heavy jaw, a low shoulder, and bad 
action in the hind-quarters, and the vendor volunteered the information that it was very hard in the mouth.

'I took the horse upon its appearance, without trial or examination, beyond an inspection of its legs and eyes at the stable-door. At first I found it the most disagreeable mount I had ever tried. It had no elasticity, no animation, and gave but little response to the bit. Once, when I had coaxed a sort of gallop out of the creature, it bolted into a wall, to the damage of both rider and horse.

'But the rigid jaw soon became flexible under Baucher's system; and the whip and heels soon brought the hind-legs under the body, and gave good action to the croup. Then, for some weeks, the horse was daily ridden at a slow pace, while hand and legs worked to bring about united action of the extremities.

- When this was accomplished the animal was metamorphosed. From a dull, ungainly, and obstinate brute, it became a light, active, and obedient mount, ready and able to answer to every demand of the rider.

' This horse, that a few months ago was hardly fit to draw a plough, now moves with lightness and grace in any direction, has fine action in all the paces, will trot in a circle of less than two yards' 
diameter, and changes the lead in the gallop with precision. With the spurs pressing upon its flanks, it would not break a thread against the bit, and it has no will of its own.

'The suppling and united action of the extremities have made the horse sure and safe in leaping, and I have never known it to refuse a leap, either from a halt or a rapid pace.

'I selected this horse, and I have described my experiences, to show the value of a systematic method of training. I have done nothing that would be impossible to any patient horseman, and I have formed a horse that is perfect for any purpose.

' The natural defects of the animal have not been cured, although it has very greatly improved in appearance: the heavy jaw and the low shoulder remain, without, however, being indicative of an obstinate will or bad action. I should like very much to show you the results of my labour, and it will give me pleasure to ride the horse for any gentleman who takes an interest in the training of horses, and who would understand my objects. The horse is not for sale. I do not sell horses. I desire to do what I can towards introducing better and more systematised methods of schooling horses than those usually employed. 


\section{The Intelligence of the Horse.}

In point of intelligence, the horse is undoubtedly second among our domestic animals, although it is very far below the dog in reasoning powers. Most of the anecdotes that are related to show the sagacity of the horse are really examples of the rare instinct it possesses; and while it is not uncommon to find horses that exhibit marked dislike for certain persons, I think that the animal is incapable of any real attachment to persons, while the preference it shows for places where it has been well fed and sheltered is common to beasts of a much lower order of intelligence. The horse readily learns the meaning of words, but it does not seem to anticipate the wishes of its master in anything like the degree that the dog does, and the tricks taught to the horse by patiently persisting in certain routines are always perfunctorily performed. But the memory of the horse is one of its most striking attributes, for it hardly ever forgets persons, places, or incidents, particularly those of an alarm- 
ing kind. A nervous timidity renders the horse untrustworthy, and this characteristic is more strongly marked in animals of the highest breed, for, contrary to the generally accepted opinion, I think that the more 'spirited' the horse the more apt it is to give way to panics. It has always appeared to me that the coarser-bred horses show more intelligence than those of higher lineage, and I have never seen thoroughbred animals that compared, in what we may term reasoning powers, with those used for heavy draught. I have asked the opinions of some of the first trainers in Europe upon this question of the relative intelligence of the different breeds, and found them about equally divided; those who pronounced in favour of the thoroughbred horses were influenced, I think, by their belief that such animals were more readily taught tricks, by reason of their more sprightly dispositions, than those more coarsely bred. This effort, on my part, to obtain some authoritative expression of opinion leaves the question in statu quo, and in support of the belief I hold I can only relate certain cases that have come under $\mathrm{my}$ observation. A year or so ago I had a coarsely bred horse in training as a school horse, which I taught to shut the door of the manege. This was simple enough, as it might have been a mere 
matter of routine, but I was surprised to find that, on being taken to new places, the animal would, merely at the word of command, go and shut any door that happened to be open. Simple as was this performance, it showed a higher intelligence than any incident that I can at present recall, for it proved that the horse understood the words of command, and by a mental operation obeyed the directions with regard to unaccustomed things. A remarkable case of instinct, as differing from reasoning, is that of a thoroughbred horse belonging to Mr. James Hunter, riding-master in Edinburgh, which could select from a long row of similarly built houses one that had no distinctive marks, in which lived a lady who fed it on sugar. Now this horse had either the reasoning powers of being able to count from the beginning of the row, which is an absurd proposition, or by some instinctive feeling was led directly to the place. The intelligence that directs horses to a desired point over an unknown country is of the same kind as that which governed Mr. Hunter's animal, and, like the same quality that more particularly distinguishes the homing pigeon, cannot be satisfactorily explained. If the actions of one of the large horses of a brewer's team be observed as it lets down the full barrels into a cellar and draws up the empty 
barrels, we must be struck with the intelligent manner in which the animal performs its duties; and it is among horses of this class that I have always noticed the things which seemed to me to show certain reasoning powers; but even these were never of a kind that would suggest that the animals could be depended upon when beyond the disciplining influence of the reins. The tricks of performing horses, directed by indications of the trainer's whip, exhibit careful training, but do not prove superior intelligence, and even Signor Corradini's horse Blondin was a mere machine that moved only under the direction of its master.

To obtain unfailing control over the horse, we cannot depend upon its voluntary obedience, and we must cultivate its involuntary muscular actions, by which its movements are placed under our will. The 'liberty-horse' that is outside of the range of the trainer's whip follows its own inclinations, but the animal that has been drilled to yield to the bit and answer to the spur obeys the indications of the aids without reasoning and without resisting. This control over the horse can be established only by long, patient, and carefully-directed work, and it is foolish to suppose that any horse-taming methods - some of which are effective enough in proving to a wilful colt the inutility of struggling against its 
master-can in a few hours teach the animal the authority of the bit and the power of the spur, for the 'tamed' horse is as ignorant of everything connected with usefulness after it has been treated as it was before. 


\section{Shoeing the Saddle-Horse.}

No horse should be sent to the forge unless attended by some one who knows how it should be shod, for even if the smith understands his business -a violent presumption, it is not likely that he will take the trouble that must be required for properly doing his work, if left to his own devices.

In the first place, all of the hoofs should be prepared for the shoes, so that the horse has a perfectly level bearing. The toes of the horse should point forward, and the slope of the hoof over the toe should conform to the slope of the pastern. In order that the horse may have safe action, it is imperatively necessary that the hoofs should be properly prepared, for any defect that is in the bare foot will be magnified in effect when the shoe is applied. If the horse turns out a toe, the wall of the hoof is too high on the outside; if the toe is turned in, the wall of the inside of the hoof is too high. It is almost impossible to trim the hoof by the eye so that the bearing will be por- 
fectly level, and Mr. S. T. Harris of Cincinnati, a grentleman who has devoted years of intelligently directed study and experiment in shoeing the horse, suggests the following plan. With a pair of compasses the distance is measured from the middle of the outside heel, at the ground, to a point on the outside quarter of the lower edge of the hoof, and this point is then marked with a pencil. From the middle of the inner heel, where it touches the ground, the same distance is measured upon the inner quarter of the lower edge of the hoof, and this point is marked by a pencil. From the first-made point on the outside quarter of the hoof, the distance, in a perpendicular line, is measured to where the hair and hoof join, and the length of this line, compared with the perpendicular line measured from the second-made point to where the hair and hoof join on the inner side, will give the exact difference of the heights of the walls of the hoof at those corresponding points. A point on the front of the hoof at the ground, equidistant from the two points first marked on the quarters, will give the position of the toe, and from these points the measurements can be made that will show exactly what shall be taken from the hoof to give the horse a level bearing.

When the hoofs have been prepared, the shoes 
of unvarying thickness throughout, and having the groove in which the nail-heads are to lie carried from heel-point to heel-point, should be fitted and fastened on with no more than five nails each. The horse will then be properly shod, particularly if the smith be prevented from rasping the hoofs when the nails have been clenched.

If the toes are so short that the angle made by the front surface of the hoof with the ground is less than that made by the front of the pastern, the shoe must be thickened at the toe and gradually diminished towards the heels. If the angle made by the front surface of the hoof and the ground is greater than that made by the front of the pastern, the hoof at the toe is too long, and, if no horn can safely be taken from the hoof, the shoe should be thicker at the heels until the hoof grows out.

Where the deformities of turned-out or turned-in toes are very great, they should be very gradually corrected at each shoeing of the horse; and, in the case of old horses, it is perhaps better to be satisfied with partially curing the defects, going far enough, however, to prevent blows upon the pasterns and insecure treading. If horse-breeders would look after their foals, and make occasional use of the rasp upon their hoofs, we should not often find 'pigeon-toes' or splay-feet in horses. 
If a horse that has always gone safely takes to tripping, it is, unless due to weakness, because the toes of the hoofs are too long or too short, for it must be remembered that a horse that is thrown upon its toes by being too high at the heels is just as apt to trip as the horse that has the toes too long.

If a horse strikes a leg with the corresponding hoof of the opposite side, it is because the hoofs are not level in their bearings.

If the horse strikes a fore-leg with one of the hind hoofs, it has been badly ridden, and the animal should be made to go in a collected manner between hand and spurs, which will induce higher action in front, and shorten the strides.

If small calks are used on the heels of the hind shoes, the toes of those shoes should be thickened so that the feet will have a level bearing.

The horse should be shod at least every three weeks, and oftener if the shoes are much worn. If the shoes are permitted to remain too long, the hoofs cannot spread as they grow, and there is not only danger of producing disease, but the most sure-footed horse may fall from soreness in the feet caused by pinching shoes. I have known a horse, fourteen years old, that had never made a mis-step of any consequence, to fall when walking 
on a perfectly smooth road, and an examination of its feet showed that inflammation had been caused by shoes that had not been removed for a long time.

It is better to use the rasp in preparing the hoofs, as there is less danger then of taking away more horn than is required, as sometimes happens in using the knife, and the bars at the heels should never be cut away.

It must be understood that what I have said regarding the cure or the correction of such defects as toes turned in or turned out, have reference to horses naturally well-formed, whose hoofs have been neglected. But where these defects are due to malformations they can be remedied to a greater or less extent in the same manner. 


\section{The Test of Horsemanship.}

AN Englishman usually has a contempt for the horsemanship of any other country, because it is popularly supposed that it is only the men of Great Britain who can ride to hounds, and the ability to keep in the first flight is taken as the test of skill in riding. But to shine in the huntingfield requires other conditions than mere skill in riding, such as strong nerves and muscles, a knowledge of the country, and long practice in the sport. and these are so essential that there are many in stances where men have excelled in riding across country who had neither good hands nor good seats, and some even where riders who never took a jump were enabled, by their acquaintance with the face of the country and the nature of the chase, to be in at the death with the regularity of the 'bruisers.'

To ride a horse in the gallop or to sit it over an obstacle does not imply the highest form of horsemanship; and even were these tests of good riding, 
there have been visitors from nearly every country of Europe, who have ridden well and boldly in the hunting-fields of England.

The man who 'takes his horse by the head,' and pushes it boldly at a six-foot wall, finds himself ' at sea' when mounted upon a well-bitted hack, and I have heard of more than one fox-hunter who could not ride the light-mouthed Spanish-American horses. If the cross-country rider has a seat that will permit him to ride over obstacles without the support of the reins, he has one of the attributes of a good horseman, that is, a firm seat. But he must still prove that he has the knowledge of how to control the movements of the horse before he can be held accomplished in the art. If it be admitted that a man can ride well across country without possessing good hands and an unexceptionable seat -leaving out of the question an accurate knowledge of the use of the aids-it follows that a good horseman may be a good man to hounds, but not that a good man to hounds is necessarily a good horseman. So prejudiced are some minds against anything that looks like art in horsemanship, that 1 have known accepted authorities upon the subject to say that a schooled rider would not be able to ride to hounds as well as one who has learned riding through his unaided efforts; as if a man who 
had the nerve and experience necessary to excel in a sport would be any the worse for a better acquaintance with one of its conditions.

The vulgar idea of a school-rider is that of a public performer in the circus-ring, or of one who limits his equestrian exercises to the covered manege. The true meaning of the phrase is, one that controls his horse by a certain method, in which nothing is done without reason. The trouble that it takes to acquire any art has deterred the many from practising riding according to the best methods, and they have formed the prevalent opinion that such methods are useless. The fact is that all soldiers are schooled riders, and all cavalry horses are schooled horses, and there is no class in England who manage horses so well as the military, even tested by the hunting-field.

A man might be a school-rider, and yet not ride so well or so strongly as one who has never received instruction in the art, for if the former had no aptitude for the exercise, all his theory would not make him a practical horseman. But of two men with equal aptitude and equal practice, there can be no doubt that the one who received proper instruction in any art must be superior to the other. And yet this is what those who disparage schooling really deny. 
No sport or mode of riding in which any other element than the mere management of the horse enters can properly be the test of horsemanship. It would be as fair to say that ostrich-chasing, kangaroo-hunting, or cow-herding-in each of which special knowledge is required-should be the test, as to fix upon cross-country riding. Nor would I suggest the airs of the manége as the measure of a man's skill in riding. If the object in riding is to control the horse, that control is the true test. This would require the best possible seat, so that under all circumstances the rider could employ the proper aids, and to give the aids properly would imply a thorough knowledge of the art.

In Austria, in Prussia, in France, and in Italy, nearly every one who rides practises the exercise according to some good method, and it is an error, into which the majority of Englishmen fall, to believe that there are not many very accomplished horsemen in those countries, horsemen who, as far as seat, hands, and the control over the horse are concerned, would compare favourably with the best riders in England. It is folly to underrate the cavalry of the Continent, although it is not gathered from the hunting-field; and, from what I have seen of its influence upon the riding in England, I am 
disposed to think that the less the influence of the hunting-field is felt, the better it is for the art of horsemanship. Not, be it understood, that I think there is anything in cross-country riding per se (a manly and an invigorating sport) that is incompatible with the best horsemanship, but because as soon as a man can ride a horse in a gallop over a hedge, he thinks that there is nothing left in the art for him to learn, and so, through the huntingfield, managing a horse is falling into neglect.

Leaping is practised much more upon the Continent than is usually admitted in England, not only in steeple-chases and in hunting, but the cavalry soldiers are trained to ride across country, and to take such obstacles as present themselves; but these riders are first taught to manage their horses properly, and jumping is but an incident in, not the whole end of, horsemanship.

It is the common remark of foreigners that the women of England ride much better than the men, and this is, without doubt, owing to the fact that women as a rule are instructed in riding. With such teachers as Mr. Fred. Allen and Mr. Edwin Axtens, who have no superiors in Europe in imparting the proper method of obtaining a seat in the sidesaddle, it is not surprising that in the Row may be seen women who ride marvellously well. But their 
cavaliers do not always show to advantage, for, though they may be firm enough in the saddle, which is not always apparent, a really graceful horseman is the exception even in the height of 'the season,' when the best riders as well as the worst may be supposed to be in the Park.

I do not wish to have it understood that I am of the belief that there are no good horsemen in England, for such is not the case. I mean to say that thoroughly good riders are rare, and are not confined to any country, and that it is not every one who rides to hounds or airs himself in the Park that can be considered a fine horseman. I may be asked, if such is my opinion of the horsemanship of England, how it is that this country furnishes the best jockeys in the world; and I shall answer that I do not consider the performances of those men to be riding in any sense of the word. The very slightest knowledge of the bit is required, and none at all of the spur, to put any one with a small appetite and a knowledge of pace upon an equality with the most successful jockey.

Although I have been bold enough to say that there are riders in other countries who can equal those of England, I draw the line there; for in everything else connected with horses, in their breeding, their rearing, and their care, I believe 
that Englishmen stand unrivalled. No one can yoke horses together, or drive them, as well as an Englishman; and in England one may get the best saddle, or any other thing belonging to the furniture of a horse that is best. 


\section{How to Buy a Horse.}

THE only way to guard against disappointment in the purchase of a horse is to have a fair trial while the animal is kept in the stable of the buyer. This precaution will be well worth the extra price that must be paid for the animal, and if the vendor is unwilling to agree to it, the probability is that the horse has some fault which he wishes to conceal. There are some dealers who object to sending out a horse on trial, because, if it becomes known that the animal has been returned, its marketable value is thereby decreased. But if the horse has been returned, it was because it did not suit the intending purchaser, and the dealers must not expect to have every advantage on their side. Warranty is no real safeguard, for the majority of dealers will not hesitate to give a good character to the most worthless horse, in the hope that the expense and annoyance of a suit at law will deter the victim from bringing an action; and the proverbial 'difficulty of suiting a gentleman with a horse' excuses 
these men in the eyes of the public if any complaint is made against them. It is foolish to hope that, by going to a 'respectable' dealer, one may be certain of getting a good horse for a good price. If a dealer can sell an inferior horse for a long price he will do so; and there is no dealer who does not occasionally find that he has worthless horses on his hands. I have bought experience of dealers in purchasing horses in England, America, France, and some other countries, and I have never found a man who had horses to sell feel bound to protect the interests of the buyer. If a man trades in horses to obtain a livelihood, he would bring himself into a state of bankruptcy if he exposed or admitted the defects of his horses. The plan, then, of demanding a trial would apparently bring ruin upon those who are engaged in horse-dealing, for they would be unable to dispose of their bad bargains; but the increased prices that good horses would bring in might, in a measure, balance such losses, and, besides, we are considering the subject from the purchaser's point of view. There is no one so expert in judging the value of horses that he can decide without trial upon the usefulness of an animal. Of course there are visible defects that may prove at the first glance that the horse is incapable of doing work, but there are many horses 
that are worthless in which their defects are not easily discovered. A horse with apparently fair action, and without bearing any marks upon its knees, may stumble in a manner that must in time bring it down. A horse may be quiet to ride, and yet have stable vices that render it dangerous, or that will produce incurable disease.

If the horse is in every way satisfactory after a trial of two weeks, and is passed practically sound by a competent veterinary surgeon, its purchaser will probably have a very useful, perhaps a very valuable, animal, particularly if by regular work it is kept from acquiring faults through idleness.

If the buyer is not able to pay the dealer the extra price that would be required for the trial of a horse, he may go to the breeder or to the auctionmart for what he requires. From the former he can obtain a sound young horse for a comparatively small sum, and he can either train it according to his own ideas, or place it in the hands of some experienced and careful man until its education is completed. If he elect to follow the latter course, he could not do better than to obtain the aid of Mr. E. J. Axtens of London, or of Mr. Charles Toop of Bournemouth, or of Mr. William Brien of Edinburgh, or of the Messrs. Burgess of Harrogate. I believe that any one of these would, if he under- 
took to do so, 'make' a young horse pleasant and safe to ride, and the owner may trust implicitly in all that is told him regarding the animal. I do not say that there are not many others who are perfectly competent to school young horses, but I can recommend those I have named, from a knowledge of their methods.

To buy a horse at an auction sale is to take a chance in a lottery. Many excellent horses are sold in those places, but to them are also sent most of the vicious, worthless brutes that cannot be disposed of in any other way. The price is often an indication of the value of a horse sold by auction, for it is seldom that a really good animal is friendless; but occasionally a very fair horse may be picked up for a sum far below its worth. It is not usual to give any warranty to horses sold by auction, and some of those that are described as fine 'performers across country,' 'quiet to ride and drive,' or 'well known' with this or that pack of hounds, may answer those descriptions as far as they go, and yet be vicious in the stable, difficult to mount, or otherwise dangerous.

It is a common error to believe that horses which are quick and clever upon their feet may trip without danger of falling, and many men select horses with low action as being less liable to tire than 
those which raise their feet high from the ground. No horse that trips is safe to ride, and while horses of extravagant action soon become leg-weary, there is a medium between these classes in which safety lies. In all of its paces the horse should raise each foot clear of the ground, and plant it flat and firmly ; the action should be true, even, and free. The opinion of a veterinary surgeon should be taken upon the condition of the animal, and he should be asked specifically whether the horse has corns, contractions, or any defects in the feet, and whether the back tendons are in any way affected, for horses are often pronounced 'sound ' when they are really unsafe to ride, by reason of weakness in the forelegs or of some faults in the feet that may not render them technically unsound. It is a severe test of the manners of a young horse to ride it when 'fresh' after a rest of two or three days, and if it have any vice, tricks, or bad habits, they will probably be shown under such circumstances. A spirited animal will almost invariably jump about and make a few curvets, perhaps make a pretence of being shy; but if it be not violent, and after a short time becomes steady, it may be presumed to be of a good disposition. Riding a horse with a loose rein over rough ground is not always a test of its sureness of foot, for some horses will take 
care of themselves under such circumstances, and stumble on perfectly level roads. A timid or an inexperienced rider should not mount a young horse, for horses that have not been thoroughly disciplined are always ready to take any advantage of such a master, and an animal that would become perfectly quiet in the hands of a determined man may acquire dangerous tricks with one who is irresolute. As I have before said, the form of the horse frequently indicates the animal's disposition. and I may add that its temper is often shown in the expression of its face. The purchaser should therefore avoid horses with roach-backs, ewe-necks, disproportionate height at the withers or the croup, faces that are either too concave or too convex in profile, as well as those which look about them in a restless and suspicious manner. There may be horses with any or several of these defects that are safe and pleasant to ride, but they are the exceptions. If one rides for health or amusement, it is hardly wise to mount a vicious or unruly horse, and although a young man who has a firm seat, a skilful hand, and perfect confidence in his nerve may find satisfaction in obtaining control over a difficult horse, it is better, as a rule, to leave such work to those who make it a profession. It is much easier and safer to break and train a colt than 
to correct the faults of a horse that has been spoiled by a former rider, and my advice to the amateur is not to attempt the latter, nor do I think it prudent to purchase a horse, no matter how quietly it may gro during its trial, that has ever been really vicious. One may often hear men of small experience in riding boast that they are able to manage any horse, but the best horsemen I have ever seen did not have such confidence in their powers, nor do I believe that any man can sit an active horse, in an ordinary saddle, if the animal understands how to exert itself. Fortunately, most horses are im pressed with the idea that plunging, kicking, and rearing are the best methods of getting rid of a rider, and, when these fail, they accept their defeat and go quietly until they feel that they are in the hands of some one less experienced, when they may repeat the same tactics. But when it occurs to the mind of a wily horse to put its head between its fore-legs, to arch its back, and then, after coming to a stand-still, to 'buck' violently, the rider must go off, and the saddle, with girths still buckled and intact, may follow him. Buck-jumping horses are rare in Europe, but I have seen such in England and in Germany. In buying a horse, one should not mistake nervousness for mettle, dulness for docility. The horse of mettle has such courage- 
always of a limited kind-as those of its race may possess; the nervous horse is a coward, and is given to panics. The docile horse accepts correction without resentment ; the dull horse is wilful and headstrong. It can readily be understood that a horse that is good in every respect may be difficult to find; but if young horses were properly broken, those that turn out badly would be comparatively few ; and if men who breed extensively would take the trouble to have their horses well disciplined before they are offered for sale, they might expect, and would deserve, highly remunerative prices for all the animals they could bring into the market. 


\section{A Model Riding-School.}

The tedium of riding about in the 'dull round' that is the custom in most riding academies has deterred many who would like to receive instruction in horsemanship from taking lessons, and, while the usual charges are low enough if the pupil could really learn 'the whole art of managing the horse in twelve easy lessons,' they are much too high for the kind of instruction that is usually offered. If I should write a description of all that I think a riding-school should be, it would be said that I suggested something that was impracticable. I will, therefore, give an account of the manner in which the school of Stallmeister Fritz, of Stuttgart, is carried on, as an example of what may be done in the way of interesting pupils, as well as of improving them in the art of horsemanship.

In the first place, Herr Fritz is a thorough horseman, having been graduated from the celebrated Royal Hanoverian School as a Master of Riding; 
and for twenty-five years he has followed his profession in the manege that his father had conducted for a like term before him. Herr Fritz has a theoretical and a practical knowledge of all kinds of riding, is equally good in demanding the 'high airs ' from a schooled horse, or in teaching a young animal the discipline of hand and heel, and he is quick in learning the tempers of the horses he rides.

The horses of the school I mention are good enough for the purpose for which they are intended, and-what should be the rule in all schools, but one which is more honoured in the breach than in the observance-they are taught to go equally well to either hand, in the walk, in the trot, and in the gallop.

The price of a single lesson is but half-a-crown, and that for a course of twenty lessons is two pounds, about one-third of the tariff usual in Great Britain, and this in a country where many-if not most - of the saddle-horses are imported, and where the cost of keep cannot be particularly cheap. That these prices are remunerative is proved by the fact that the school has been in a flourishing condition for about half a century, in a city that at present numbers but little more than one hundred thousand inhabitants. 
The school is open from an early hour in the morning until nine o'clock in the evening, the hour from eleven to twelve being reserved for ladies, but ladies can and do ride at any time.

As far as is possible, the pupils are kept in the classes best suited to their proficiency, for as soon as the beginner has acquired the rudiments of the art, he or she is put to 'figure-riding' as the best means of giving a knowledge of the use of the aids. In the junior classes these figures are easy and simple, but they prevent the lesson becoming monotonous. As the pupils advance in skill, the figures become more complex, and many of them -demanding the 'travers,' the 'voltes,' and other school movements-are performed at the gallop. I have seen a class of twelve ladies go through a complicated quadrille, in the trot and in the gallop, with a precision that proved great skill in each rider.

The advanced 'classes,' and the clubs that are formed in the school, often ride their quadrilles to the music of a band, the airs being selected to be in cadence with the pace in which each figure is performed. These musical rides are very effective, and give much pleasure to the pupils and to their friends who come to look on. The principal association that has had its origin in the manege of Herr 
Fritz is the 'Stuttgart Reit-club,' which has the honour to form the civil escort of the King of Würtemberg on state occasions. This club, now about to celebrate its tenth anniversary, has a weekly reunion at the school, and on parades it appears in a modest and appropriate uniform.

The step from figure-riding to the movements of the high school is but a short one; indeed, many of the latter are required in the quadrilles, but those pupils who wish to carry their education into the highest branches of horsemanship find a most competent instructor in Herr Fritz.

Horse gymnastics form another course of this school, and Herr Oscar Fritz, a bold and very accomplished rider, gives practical lessons in la voltige and those exercises that make the pupil ready and active in mounting the horse and in maintaining his seat.

Instruction and amusement are also combined in tilting, or taking a suspended ring upon the point of a sword or a lance while in full career; in casting darts from the back of a galloping horse against a wooden target that is placed in the manége, and in other games that teach the rider to be master of his own movements and those of his horse.

On the whole, I think that a pupil might, with pleasure and profit, take a long course of lessons in 
such a school as I have described; and it might be advisable for the riding-masters of Great Britain and of the United States to make their schools more attractive by following the example set by Stallmeister Fritz. 


\section{The Changes in the Gallop.}

Although every work on Horsemanship gives instructions for inducing the horse to make the changes in the gallop, if anything is known of how and when these changes take place, there is no record of it in the books. The only writer who has, to my knowledge, made any original remarks upon the manner in which the horse changes in the gallop, is the author of The Horse in Motion, who suggests that there is but one mode of changing, and that it takes place when the horse is in air. But there can be no doubt that there are two modes by which the horse changes lead, and I think that I can show that neither of them takes place wholly while the horse is free from the ground.

That the horse can change by beginning with the fore-legs is proved by the fact that the animal frequently makes the change in the fore-hand while the hind-legs keep in the old order. That it can change by beginning with the hind-legs is proved by the fact that the changes can be made truly at 
every stride, which would be impossible if the change began in the fore-legs, for by the time the fore-legs are ready to make the change, the hindlegs must be committed to a certain order so that they may receive the weight.

The horse cannot make the changes wholly when in air, because that position is kept for too short a time, and because the hind-legs must be prepared to receive the weight in one or another order of precedence before the animal leaves the ground from the leading fore-leg.

In all forms of the galloping pace (except in the canter), the horse is ready, at the moment it goes into air, or when it plants the fore-foot from which it goes into air, to make the change of lead,-in the latter case completing the change in one stride, in the cadence of the pace; in the former, taking two or more strides in which to change, by which the cadence is more or less interrupted. In the canter, by reason of the outer fore-foot being planted before the inner hind-foot, the change can be made in the cadence of the gait only by beginning with the hind-legs; but if the fore-hand is sustained when the weight is first taken in the stride by a hind-leg, the change can be made by the other mode, in which two or more stricles are required. 
I will, by referring to the numbered figures ${ }^{1}$ of the horse, explain more fully the two modes by which the horse changes lead. First, when the horse begins to change with the hind-legs (I am describing more particularly the gallop of three beats, but the analogy holds good in all forms of the gallop), the intention must be formed (Fig. 6) before the centre of gravity has passed over the fore-leg from which the animal is going into air. When that fore-leg has taken the weight, the hindlegs are changing (see Fig. I); and when the horse is in air the hind-legs are committed to a certain order (see Fig. 2). The fore-legs begin to change either when the horse goes into air, or after a hind-leg has received the weight, depending upon the state of poise in which the mass is carried along; the more languid the pace, the sooner the change must be begun in the fore-hand. The feet will thus be brought to the ground in the regular order (see Fig. 3), and the change will have been made in one stride without a false step. This is, I think, the mode that horses usually follow when at liberty, for instinct would lead the animal to adopt the manner of changing which is in accord-

1 Figures 1, 2, and 3 represent the horse in the change beginning with the hind-legs. Figures 4,5 , and 6 represent the horse in the change beginning with the fore-legs. It must be borne in mind that the horse is false hehind in Figures 5 and 6. 

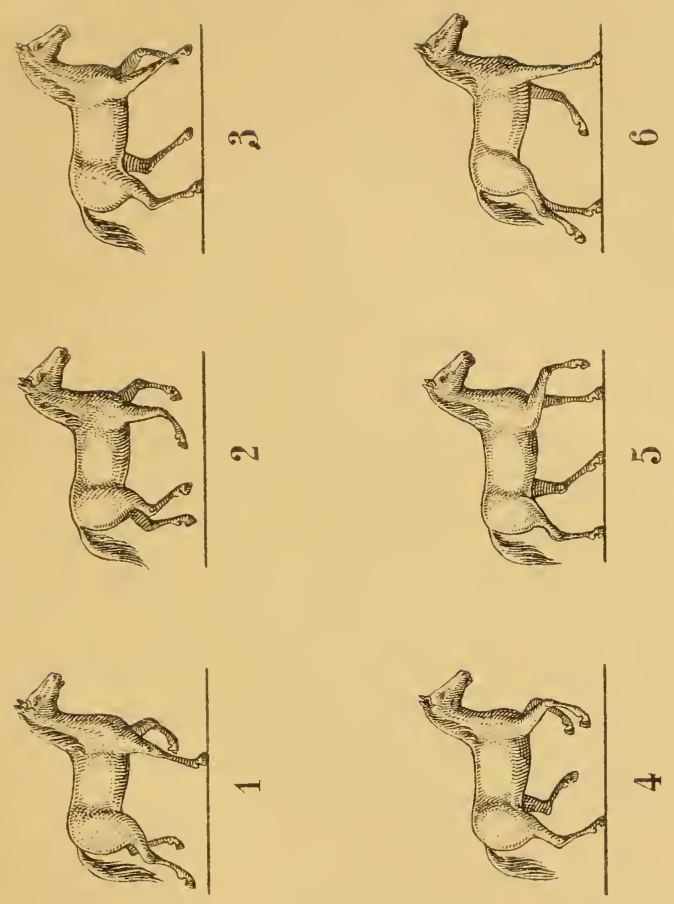

ance with the action of the pace, and by which the bearers are best prepared to support the centre of gravity, but that it is not always the case I an assured. It is also the better mode of demanding the changes from the trained horse, for the same reason, and because it does not break the cadence, because it does not give a false stride, and because it keeps the animal true to the line of direction.

Figures 4, 5, and 6 illustrate the second mode of changing, when the change begins with the forelegs. In this case the fore-legs may begin to change at the moment they are free, and the horse has gone into air, but not much can be effected before a hind-leg has taken the weight (see Figs. 6, I, and 4). When the fore-hand comes down, the fore-legs have been changed, but the hind-legs follow the old order, and the horse is false behind (see Fig. 5). When the centre of gravity is about to pass over the fore-leg from which the horse will go into air, the hind-legs begin to change, and the horse will be true in the new lead in the stride that is thus entered upon.

Schooled horses usually make the changes at first by the latter method, and, as they learn to obey the aids with readiness, they fall into the first-described and better mode; and it is only by beginning with the hind-legs that the changes at each stride can be 
made. But I am not aware that any writer has observed that there were really two modes of changing, or that either of them has ever been described before I attempted it,--here, in my book on 'The Gallop,' and in my letters to the Illustrated Sporting and Dramatic News.

I have formed my theories of the changes in the gallop from my experiments in photographing the moving horse, from riding horses in the changes, and from watching the training of school horses, and from all these tests I feel confident that they are correct in every particular.

Although the books do not mention that there are two distinct modes of changing, I think that some riders are aware of it. After I had satisfied myself that there were two, I asked a number of professional riders in how many ways a horse could change, and I found one, Herr Wilhelm Jetter, of Stuttgart, who told me that when he felt that in changing his horse was false in the second beat (Fig. 5), he knew that the change had been begun in the fore-hand, and that when the change was smooth he knew it had been begun by the hindlegs; but he did not profess to know, what the camera alone could disclose, how the horse moved its legs in changing, and exactly when the change began. 
It is important that the rider should be aware of the moment the change should be begun, and, from the little that is known upon the subject, horsemen must be largely directed by practice in finding the best way of giving the prescribed aids; and that this is true is shown by the fact that school horses in their early training usually begin to make the changes with the fore-legs, and after the rider and the horse come into better accord the changes are begun by the hind-legs. And I have often seen a horse, when the changes were made a number of times, use first one mode and then the other. After the reader fixes in his mind the differences of the two modes, his eye will plainly show him by which a passing horse is changing.

To procure the change of lead beginning with the hind-legs, the opposite spur should be applied as the leading fore-leg comes to the ground, so that the hind-legs will begin to change as they are freed from the ground (Figs. 6 and I). The direct rein should make play as the centre of gravity passes over the leading fore-leg (Fig. I). The lower the action of the horse the more closely together must be the effects of the aids; in the canter they must be used together; in a well-united gallop of three beats, and in the school-gallop, the hand should act after the spur has had its effect. 
Before teaching the horse this mode, the animal must be taught to gallop with either side in the lead at a very slow pace, and at first the demiarret (or half halt) may be observed as the forehand comes down in the stride, but the horse will soon learn to make the change without interrupting the cadence of the pace. Whenever the opposite spur and the direct rein are used, the other spur and the other rein should measure their effects so that the horse will not be too much bent or have too much liberty of action.

\section{Note.}

At liberty, the horse, I think, begins, in either mode, to change the fore-legs while in air, except where the animal comes to a half halt, as it does sometimes in changing direction. In the canter, the horse, whether at liberty or under the saddle, must change the fore-legs while in air, if anything resembling the cadence is observed. But when the rider demands the changes in the ordinary gallop of three beats (or in the school-gallop), the effects of the aids and of the weights are such that the fore-legs do not usually begin to change until a hind-leg has taken the weight (Fig. 4). I have 
never had a photograph taken of the horse while in the act of changing, but I hope, in a future edition, to be able to furnish instantaneous pictures of the horse changing lead in both modes. 


$R B C$

Tandlan Kogers

798

$A_{n 3}$ 

